\title{
Wholegrain oat-based cereals have prebiotic potential and low glycaemic index
}

\author{
M. L. Connolly ${ }^{1}$, K. M. Tuohy ${ }^{1,2}$ and J. A. Lovegrove ${ }^{1,3 *}$ \\ ${ }^{1}$ Department of Food and Nutritional Sciences, University of Reading, Whiteknights, Reading RG6 6AP, UK \\ ${ }^{2}$ IASMA Research and Innovation Centre, Fondazione Edmund Mach, Food Quality and Nutrition Area, Via E. Mach, 1, \\ 38010 S. Michele (TN), Italy \\ ${ }^{3}$ Institute for Cardiovascular and Metabolic Research (ICMR), University of Reading, Whiteknights, Reading RG6 6AP, UK \\ (Submitted 30 June 2011 - Final revision received 16 January 2012 - Accepted 16 January 2012 - First published online 24 February 2012)
}

\begin{abstract}
Population studies show a positive association between increased dietary intake of wholegrains and reduced risk of cardiometabolic disorders. Consumption of wholegrain food has been associated with lower blood glucose and therefore may contribute to a low-glycaemic load diet. The ability to mediate a prebiotic modulation of gut microbiota has recently been suggested to have an inverse correlation with risk of cardiometabolic disease. To date very little work has been carried out on the functionality of wholegrain breakfast cereals in terms of glycaemic response or impact on gut microbiota. An investigation into identifying wholegrain-based breakfast cereals demonstrating both low glycaemic index (GI) and prebiotic attributes was performed. After in vitro digestion, cereal samples were supplemented to $\mathrm{pH}$-controlled anaerobic batch cultures of the human faecal microbiota. Total bacteria populations increased significantly $(P<0 \cdot 05)$ in all treated cultures, and the fermentation of a wholegrain oat cluster cereal was associated with proliferation of the Bifidobacterium genus $(P=0.02)$. Smaller, but significant increases in the Bifidobacterium genus were observed for a further four oat-based cereals. Significant increases in the Lactobacillus-Enterococcus group were observed for granola $(P=0.01)$, 100\% wholegrain aggregate $(P=0.04)$ and $70 \%$ wholegrain loops $(P=0.01)$. Cereals demonstrating prebiotic potential were selected for GI determination in twelve healthy subjects. The wholegrain oat aggregate cereal achieved the lowest GI value (40), three other cereals ranged between 44 and 74, with instant porridge resulting in a GI value similar to the standard glucose control. The present study suggests that wholegrain oat-based breakfast cereals may be prebiotics and have the potential to have low GI.
\end{abstract}

Key words: Wholegrains: Prebiotics: Glycaemic index: Metabolic syndrome

Wholegrain consumption has had a recognised negative correlation with risk of $\mathrm{CVD}^{(1)}$, diabetes ${ }^{(2)}$, obesity ${ }^{(3)}$ and certain cancers $^{(4)}$. From the early 1940 s, the US Department of Agriculture recommended the daily intake of wholegrains and, in 2008, the Food and Drug Administration allowed a health claim that eating wholegrain reduces the risk of heart disease ${ }^{(5)}$. It has been proposed that wholegrains contain a combination of bioactive components, for example, dietary fibre, phytochemicals and vitamins, that all have individual roles to play, to provide widespread protection from cardiometabolic diseases $^{(6)}$. Wholegrains have a multitude of compounds; some of these components have been individually investigated and evaluated for their role in the protective mechanisms against chronic disease risk.

The glycaemic index (GI) is a functional test that describes the quality of a carbohydrate. It is defined as the blood glucoseraising potential of a standard quantity of carbohydrate, compared with a glucose control. After consumption of high-GI carbohydrates, blood glucose rapidly increases. This stimulates the release of insulin from $\beta$-cells, required for the transport and metabolism of glucose. The extremes in circulating glucose and insulin concentrations are associated with eventual pancreatic $\beta$-cell exhaustion and increased metabolic stress $^{(7)}$. Epidemiological studies have reported association between the consumption of low-GI foods and reduced risk of CVD, diabetes and certain cancers ${ }^{(8-11)}$. One component of foods which is associated with a lower GI is the presence of intact wholegrains ${ }^{(12)}$. More recently, interest has focused on the potential impact of wholegrain cereals on the intestinal microbiota and the possible contribution of this mechanism to the observed reduced risk of cardiometabolic disease ${ }^{(13,14)}$. An imbalance of the intestinal microbiota is thought to predispose individuals to a variety of diseases and disorders, for example, inflammatory bowel disease and obesity ${ }^{(15)}$.

Abbreviations: FISH, fluorescence in situ hybridisation; GI, glycaemic index; IAUC, incremental area under the glucose response curve; RS, resistant starch. 
The term prebiotic describes non-digestible soluble fibres such as inulin, oligosaccharides and resistant starch (RS), which are selectively fermented by groups of beneficial bacteria present in the gut. The diet-microbiota association (in particular Bifidobacterium and Lactobacillus genera) is now thought to have an important role in human health ${ }^{(13)}$. One of the main by-products of gut fermentation are SCFA. Butyrate has a major role in colonocyte proliferation and differentiation, and an increased concentration has been associated with reduced colon cancer incidence ${ }^{(16-18)}$. In human feeding studies often no effect is observed, as over $90 \%$ of SCFA are absorbed in the colon and utilised by the host. It is therefore important to establish the quantity and ratio of SCFA produced on fermentation of the non-digestible components of wholegrain cereals through in vitro methods.

There are four mechanisms that have been proposed to have roles in the protectiveness of wholegrains. They are: effect on the large bowel; effect on blood glucose and insulin levels; antioxidants; and, lastly, other bioactive compounds that may differ between different wholegrains. As stated previously, most of these mechanisms have been investigated using individual components of wholegrains. Components such as dietary fibre, vitamins, minerals, lignans and phytochemicals are found in the bran part of grain or just below this layer. On refining wholegrain, the bran is removed and as a result these bioactive compounds are lost. It can be concluded that wholegrain cereal consumption at breakfast time can be associated with maintaining a healthy lifestyle and this may play a role in protection from metabolic disorders. Processing of wholegrains has previously been shown to have a negative impact on glycaemic response and to have an impact on the gut fermentation profile ${ }^{(19)}$. In the present study we used $\mathrm{pH}$-controlled, faecal batch cultures as an in vitro mixed culture system to investigate the microbiota-modulating capabilities of five different wholegrain cereals, which have been processed to differing extents, towards a more beneficial composition. Additionally we determined the GI of these different cereals in human volunteers. This is a novel investigation, which may have implications for designing the optimal breakfast cereals aimed at maintaining health-promoting activities of wholegrains.

\section{Material and methods}

\section{Substrates}

Two control samples, cellulose (Oxoid), which was not expected to be associated with bacterial growth, and oligofructose (Raftilose P95; Beneo-Orafti), a confirmed prebiotic, were included in the in vitro fermentation experiment. The breakfast cereals tested were: jumbo porridge oats (Traditional Porridge ${ }^{\circledR}$; The Jordans and Ryvita Company Ltd), 100\% wholegrain aggregate (Original Crunch ${ }^{\circledR}$; The Jordans and Ryvita Company Ltd), granola (Superfoods Granola ${ }^{\circledR}$; The Jordans and Ryvita Company Ltd), 70\% wholegrain loops (Cheerios ${ }^{\circledR}$; General Mills, Inc.) and instant porridge (Readybrek ${ }^{\circledR}$; Weetabix Food Company). The nutritional information of these cereals is listed in Table 1.

\section{Simulated human digestion of food (from mouth to small intestine)}

Cereal sample $(240 \mathrm{~g})$ was weighed into a stomacher bag (Seward classic 400), sterile distilled water $(300 \mathrm{ml})$ was added and the mix blended for $5 \mathrm{~min}$ at normal speed using a stomacher (Seward stomacher 400). $\alpha$-Amylase (Sigma) was dissolved in filtered sterilised $\mathrm{CaCl}_{2}(1 \mathrm{~mm}$; $\mathrm{pH} 7 \cdot 0)$; this solution and the blended cereals were dispensed into a $500 \mathrm{ml}$ glass Duran ${ }^{\circledR}$ bottle (Sigma). The mix was incubated at $37^{\circ} \mathrm{C}$ for $30 \mathrm{~min}$ on a shaker (IKA labortechnik KS501) set at $120 \mathrm{~g}$. The $\mathrm{pH}$ was acidified to $\mathrm{pH} 2$ with $\mathrm{HCl}(6 \mathrm{M})$, pepsin (Sigma) was dissolved in $\mathrm{HCl}(0 \cdot 1 \mathrm{M})$ at a ratio of $1: 15(\mathrm{w}: \mathrm{v})$ and added to the mix and incubated for a further $2 \mathrm{~h}$ at $37^{\circ} \mathrm{C}$, shaking. The $\mathrm{pH}$ of the mix was adjusted to 6.5 using $\mathrm{NaOH}(6 \mathrm{M})$. Pancreatin (Sigma) and bile extract (Sigma) were dissolved with filtered sterilised $\mathrm{NaHCO}_{3}(0.5 \mathrm{M})$ and dispensed into the mix. The $\mathrm{pH}$ was adjusted to $\mathrm{pH} 7 \cdot 0$ using either a strong acid or base and incubated for $3 \mathrm{~h}$ at $37^{\circ} \mathrm{C}$, shaking. Cold, sterile $\mathrm{NaCl}$ solution $(10 \mathrm{~mm})$ was added and the mix was poured into dialysis tubing (Spectra/Por $1 \mathrm{kDa}$ molecular-weight cut-off (MWCO) dialysis membrane; Spectrum) and incubated overnight at $5^{\circ} \mathrm{C}$. The following morning the dialysis tubing was replaced with fresh $\mathrm{NaCl}$ solution and incubated for a further $2 \mathrm{~h}$. The dialysis tubes were then removed and held over a clean sterile pot. The cereal mix was collected and dispensed into several $250 \mathrm{ml}$ clear plastic, metal cap containers (Barloworld Scientific) and stored at $-80^{\circ} \mathrm{C}$ overnight. The frozen samples were then freeze-dried (IEC lyoprep 3000) for 1 week to remove all fluid content.

\section{Faecal batch culture fermentation}

The fermentation profile of digested freeze-dried cereals, the prebiotic oligofructose (Raftilose P95; Beneo-Orafti) and the lowly fermented control non-prebiotic carbohydrate cellulose (Oxoid) was determined using anaerobic, $\mathrm{pH}$ controlled faecal batch cultures. Sterile stirred batch culture

Table 1. Nutritional information of breakfast cereals investigated (per $100 \mathrm{~g}$ cereal)

\begin{tabular}{|c|c|c|c|c|c|c|c|}
\hline & \multicolumn{2}{|c|}{ Energy } & \multirow[b]{2}{*}{ Protein $(\mathrm{g})$} & \multirow[b]{2}{*}{ Total carbohydrate $(\mathrm{g})$} & \multirow[b]{2}{*}{ Sugars $(g)$} & \multirow[b]{2}{*}{ Total fibre $(\mathrm{g})$} & \multirow[b]{2}{*}{ Fat $(g)$} \\
\hline & kcal & $\mathrm{kJ}$ & & & & & \\
\hline Jumbo porridge oats & 364 & 1523 & $11 \cdot 7$ & 58.4 & $1 \cdot 0$ & $9 \cdot 0$ & $9 \cdot 3$ \\
\hline $100 \%$ Wholegrain aggregate & 416 & 1741 & $8 \cdot 3$ & $67 \cdot 8$ & $26 \cdot 8$ & $6 \cdot 3$ & $12 \cdot 4$ \\
\hline Granola & 423 & 1770 & 9.4 & $65 \cdot 5$ & $19 \cdot 9$ & $6 \cdot 5$ & $13 \cdot 8$ \\
\hline $70 \%$ Wholegrain loops & 350 & 1464 & $10 \cdot 5$ & $70 \cdot 0$ & $4 \cdot 0$ & $10 \cdot 5$ & $7 \cdot 0$ \\
\hline Instant porridge & 359 & 1502 & $11 \cdot 7$ & $58 \cdot 5$ & 1.0 & 8.7 & $7 \cdot 9$ \\
\hline
\end{tabular}


fermentation vessels ( $200 \mathrm{ml}$ working volume) were prepared and aseptically filled with $180 \mathrm{ml}$ of sterile basal nutrient medium. Basal medium contained (per litre): $2 \mathrm{~g}$ peptone, $2 \mathrm{~g}$ yeast extract, 0.1 g NaCl, 0.04 $\mathrm{g} \mathrm{K}_{2} \mathrm{HPO}_{4}, 0.04 \mathrm{~g} \mathrm{KH}_{2} \mathrm{PO}_{4}, 0 \cdot 01 \mathrm{~g}$ MgSO $4 \cdot 7 \mathrm{H}_{2} \mathrm{O}, 0 \cdot 01 \mathrm{~g} \mathrm{CaCl} 2 \cdot 6 \mathrm{H}_{2} \mathrm{O}, 2 \mathrm{~g} \mathrm{NaHCO}, 2 \mathrm{ml}$ Tween $80,0.05 \mathrm{~g}$ Hemin dissolved in $1 \mathrm{ml}$ of $4 \mathrm{M}-\mathrm{NaOH}, 10 \mu \mathrm{l}$ vitamin $\mathrm{K}$ (Sigma), $0.5 \mathrm{~g}$ L-cysteine $\mathrm{HCl}$, and $0.5 \mathrm{~g}$ bile salts (sodium glycocholate and sodium taurocholate). The medium was adjusted to $\mathrm{pH} 7 \cdot 0$ and $4 \mathrm{ml}$ of $0.025 \%(\mathrm{w} / \mathrm{v})$ resazurin solution added before autoclaving. Once in the fermentation vessels, the sterile medium was sparged with $\mathrm{O}_{2}$-free $\mathrm{N}_{2}(15 \mathrm{ml} / \mathrm{min})$ overnight to maintain anaerobic conditions. The following day test substrates were allowed to dissolve in the basal medium to give a final concentration of $1 \%(\mathrm{w} / \mathrm{v})$ before inoculation of the vessels with $10 \%(\mathrm{w} / \mathrm{v})$ faecal slurry, which was prepared with pre-reduced sterile PBS ( $\mathrm{pH} 7 \cdot 0)$. Faecal samples were collected from three healthy faecal donors. All donors were healthy males aged between 23 and 31 years, and had not received antibiotic treatment for at least 3 months before stool collection, had not consumed pre- or probiotic supplements immediately before experimentation, and had no history of bowel disorders. The temperature of the fermentation vessels was held at $37^{\circ} \mathrm{C}$ by use of a circulating water-bath, $\mathrm{pH}$ values were held between 6.7 and 6.8 by the addition of $0.5 \mathrm{M}-\mathrm{NaOH}$ or $-\mathrm{HCl}$ to the vessels, $\mathrm{pH}$ was controlled via $\mathrm{pH}$ meter controllers (Electrolab260; Electrolab Ltd) and anaerobic conditions were maintained by sparging the vessels with $\mathrm{O}_{2}$-free $\mathrm{N}_{2}$ ( $15 \mathrm{ml} / \mathrm{min})$. A $5 \mathrm{ml}$ sample was taken from each vessel immediately for analysis; similarly, samples were taken at 5, 10 and $24 \mathrm{~h}$ for analysis of SCFA by GC and for analysis of bacterial populations by fluorescence in situ hybridisation (FISH). This experiment was performed in triplicate.

\section{Culture-independent enumeration of faecal bacteria using 165 rRNA probes labelled with Cy3 and fluorescence} in situ hybridisation

Changes in faecal bacteria populations upon fermentation of the test substrates were monitored using FISH. FISH was performed essentially as described by Daims et al. ${ }^{(20)}$. Briefly, faecal batch culture samples $(375 \mu \mathrm{l})$ were fixed using ice-cold $4 \%$ paraformaldehyde $(\mathrm{pH} 7 \cdot 2)$ at a ratio of $1: 3(\mathrm{v} / \mathrm{v})$ for $4 \mathrm{~h}$ at $4^{\circ} \mathrm{C}$. They were then centrifuged at $13000 \mathrm{~g}$ for $5 \mathrm{~min}$ and washed twice in $1 \mathrm{ml}$ filtered PBS. The remaining pellet was re-suspended in a filtered sterilised PBS-ethanol mix $(1: 1, \mathrm{v} / \mathrm{v})$ and stored at $-20^{\circ} \mathrm{C}$ for up to 3 months.

For the hybridisations, $20 \mu \mathrm{l}$ of each sample were pipetted onto Teflon- and poly-L-lysine-coated, six-well (10 mm diameter each) slides (Tekdon, Inc.). Samples were dried onto the slides at $46^{\circ} \mathrm{C}$ for $15 \mathrm{~min}$ and afterwards dehydrated in an alcohol series (50, 80 and 96\%, 3 min each). The ethanol was allowed to evaporate from the slides before the probes were applied to the samples. To permeabilise the cells for use with the probe Lab158, samples were treated with $50 \mu$ l of lysozyme $(1 \mathrm{mg} / \mathrm{ml}$ in $100 \mathrm{~mm}$-2-amino-2-hydroxymethyl-propane-1,3diol (Tris)- $\mathrm{HCl} ; \mathrm{pH} 8.0$ ) at $37^{\circ} \mathrm{C}$ for $15 \mathrm{~min}$ before being washed briefly $(2-3 \mathrm{~s})$ in water and afterwards dehydrated in the ethanol series. A probe-hybridisation buffer mixture
( $5 \mu \mathrm{l}$ of a $50 \mathrm{ng} / \mu \mathrm{l}$ stock of probe plus $45 \mu \mathrm{l}$ of hybridisation buffer) was applied to the surface of each well. Hybridisations were performed for $4 \mathrm{~h}$ in an ISO20 oven (Grant Boekel). Slides were stored in the dark at $4^{\circ} \mathrm{C}$ (for a maximum of $3 \mathrm{~d}$ ) until cells were counted using a Nikon E400 Eclipse microscope fitted with an epifluorescence attachment. A total of fifteen randomised views were counted for each sample.

The hybridisation was carried out as previously described by Rycroft et al. ${ }^{(21)}$ using genus- and group-specific 16S rRNA gene-targeted oligonucleotide probes labelled with Cy3 (Sigma-Aldrich) or the nucleic acid stain 4',6-diamidino-2-phenylindole (DAPI) for total cell counts. Oligonucleotide probes used were: Bif164, specific for the Bifidobacterium genus ${ }^{(22)}$; Lab158, for the Lactobacillus-Enterococcus group $^{(23)}$; Bac303, specific for the Bacteroides and Prevotella group ${ }^{(24)}$; His150, for the Clostridium histolyticum subgroup ${ }^{(25)}$; Erec482, for the Ruminococcus-Eubacterium-Clostridium (REC) cluster; and Ato291, for the Atopobium cluster, including most Coriobacteriaceae species $^{(26)}$.

\section{Quantification of SCFA by GC}

GC was performed to determine changes in SCFA concentration during the fermentation of the cereal digests; the method was adapted from Zhao et al. ${ }^{(27)}$. A quantity of $1 \mathrm{ml}$ of batch culture was centrifuged at $13000 \mathbf{g}$ for $10 \mathrm{~min}$ and the supernatant fraction removed to a fresh Eppendorf tube and then stored at $-20^{\circ} \mathrm{C}$ for up to 3 months. An internal standard of ethylbutyric acid was prepared with HPLC gradient water to give a final concentration of $10 \mathrm{~mm}$. Preparation of the external standard containing the SCFA acetic, propionic, butyric, isobutyric, valeric, isovaleric and caproic acids were added to give a final concentration of $25 \mathrm{~mm}$ to $\mathrm{HCl}(6 \mathrm{~m})$ and HPLC gradient water. Dilutions of the external standards were prepared and added to the internal standard (ratio 4:1) to give a final concentration for the internal standard of 2 mm-ethyl butyric, and a final concentration of external standards of $20 \mathrm{~mm}, 10 \mathrm{~mm}, 5 \mathrm{~mm}, 1 \mathrm{~mm}$ and $0.5 \mathrm{~mm}$. Samples were defrosted and $\mathrm{HCl}(6 \mathrm{~m})$ added (ratio 1:3) and left at room temperature for $10 \mathrm{~min}$. Samples were centrifuged at $13000 \mathrm{~g}$ for $5 \mathrm{~min}$, and the supernatant fraction was passed through a $0 \cdot 2 \mu \mathrm{m}$ polyvinylidene fluoride (PVDF) filter (Whatman). Internal standard was added to the filtered supernatant fraction (ratio 1:4). Samples were run through a 5890 Series II GC system (Hewlett Packard) fitted with a free fatty acid phase (FFAP) column $(30 \mathrm{~m} \times 0.53 \mathrm{~mm}$, diameter $0.50 \mu \mathrm{m}$; J\&W Scientific) and a flame-ionisation detector. Samples were automatically injected into a fused-silica capillary column. Carrier gas, He, was delivered at a flow rate of $14 \mathrm{ml} / \mathrm{min}$ and the split ratio was 10:1. The total flow rate was $140 \mathrm{ml} / \mathrm{min}$. Initial oven temperature was $100^{\circ} \mathrm{C}$, maintained for $0.5 \mathrm{~min}$, raised to $150^{\circ} \mathrm{C}$ at $8^{\circ} \mathrm{C} / \mathrm{min}$, then increased to $250^{\circ} \mathrm{C}$ at $50^{\circ} \mathrm{C} / \mathrm{min}$, and held at $250^{\circ} \mathrm{C}$ for $2 \mathrm{~min}$. Injector and detector temperatures were set at 280 and at $300^{\circ} \mathrm{C}$, respectively. The injected volume of the sample and standards was $1 \mu \mathrm{l}$. The SCFA peaks were integrated using Atlas Lab managing software (Thermo Lab Systems) and concentrations were calculated by comparing their peak areas with those of the standards and are expressed as $\mathrm{mmol} / \mathrm{g}$ faeces. 


\section{Measuring glycaemic index of test cereals}

A total of twelve volunteers who were non-smokers were recruited to the study. They were five women and seven men, aged 27 (range 23-31) years, with BMI of 23.3 (range $19 \cdot 0-27 \cdot 6) \mathrm{kg} / \mathrm{m}^{2}$. At baseline, all subjects had fasting plasma glucose concentrations $<6.1 \mathrm{mmol} / \mathrm{l}$. Exclusion criteria were: an active gastrointestinal or metabolic disease (for example, coeliac disease), first-degree family history of diabetes, and any medication. Pregnant and lactating women were also excluded. Written informed consent was obtained from all subjects before the study. The present study was conducted according to the guidelines laid down in the Declaration of Helsinki and all procedures involving human subjects were approved by the University of Reading's Research Ethics Committee. Written informed consent was obtained from all subjects. The participants were served each test food once and both reference foods ( $50 \mathrm{~g}$ and $25 \mathrm{~g}$ glucose solution) twice at 1-week intervals in a random order. The size of the meal was designed to provide a portion of cereal that would normally be consumed (either containing 50 or $25 \mathrm{~g}$ available carbohydrate). The subjects were asked to avoid vigorous physical activity and alcohol consumption the day before the study days. They were asked to fast for $12 \mathrm{~h}$ after their evening meal, to avoid exercise on the morning of the study, and to arrive at the Hugh Sinclair Unit of Human Nutrition by car or public transportation. A baseline finger-prick capillary blood sample was taken, after which the subject consumed the study meal within $10 \mathrm{~min}$. Finger-prick capillary blood samples were obtained at 15, 30, 45, 60, 90 and $120 \mathrm{~min}$ after the start of the meal. Jumbo porridge oats and instant porridge were prepared according to package instructions using $125 \mathrm{ml}$ skimmed milk. The other cereals were served with $125 \mathrm{ml}$ skimmed milk. All subjects consumed $150 \mathrm{ml}$ water with the test meal. A 50 and $25 \mathrm{~g}$ glucose solution was prepared (dissolved in $150 \mathrm{ml}$ water) and used as a reference and each was tested on two occasions. The quantity of test foods was equivalent to $50 \mathrm{~g}$ for all cereals except jumbo porridge oats and instant porridge when $25 \mathrm{~g}$ of available carbohydrate was given. A smaller amount of test food was used, as the size of the portion that contained $50 \mathrm{~g}$ of available carbohydrate was too large for the participants to consume within the allotted time. Capillary blood glucose was measured directly by using a glucose meter (HemoCue Glucose 201; HemoCue Ltd) that applied a modified glucose dehydrogenase method. A series of quality-control solutions recommended by HemoCue was measured every study morning; the $\mathrm{CV}$ of these measurements was $1 \cdot 1 \%$. The incremental area under the glucose response curve (IAUC) was determined for each cereal using the fasting level as the baseline and ignoring any area below the baseline. The GI was defined as the IAUC of the blood glucose response curve of a $50 \mathrm{~g}$ ( $\mathrm{or} 25 \mathrm{~g}$ ) available carbohydrate portion of a test meal expressed as a percentage of the response to the same amount of available carbohydrate from the reference food. The reference value and each subject's individual GI for each cereal were calculated. The GI for each cereal was taken as the mean of all twelve individual values.

\section{Statistical analysis}

Statistical analysis was performed using Minitab for Windows, version 15. Univariate ANOVA and the post hoc Tukey test were used to determine the significance of the effect of substrates on bacterial group populations and SCFA production. Normality testing was carried out to determine if data were normally distributed. Significant differences for changes in bacterial populations over $24 \mathrm{~h}$ between treatments were also determined. Differences were deemed significant when $P<0 \cdot 05$. The IAUC was calculated by the trapezoid rule.

\section{Results}

\section{Growth of human colonic microbiota on digested substrates}

Changes in bacterial populations after $0,5,10$ and $24 \mathrm{~h}$ fermentation with the different test substrates are shown in Table 2 . No significant changes in total bacteria or bacterial groups enumerated with the phylogenetic FISH probes were observed in the cellulose non-prebiotic fermentations. Numbers of total bacteria significantly increased in all other fermentations $(P<0 \cdot 05)$. Significant increases after $24 \mathrm{~h}$ occurred in the Bifidobacterium genus in the presence of oligofructose $(P=0.02)$, jumbo porridge oats $(P=0.03)$, instant porridge $(P=0.03)$, granola $(P=0.02)$ and $100 \%$ wholegrain aggregate $(P=0.03)$. Oligofructose $(P=0.03)$ fermentation resulted in significant increases in the Coriobacterium-Atopobium cluster enumerated by the Ato291 probe after $5 \mathrm{~h}$. Jumbo porridge oats $(P=0.03)$ and granola $(P<0 \cdot 01)$ resulted in significant increases in the Atopobium cluster after $10 \mathrm{~h}$. Granola $(P=0 \cdot 01), 100 \%$ wholegrain aggregate $(P<0.01)$, instant porridge $(P \leq 0.01)$ and $70 \%$ wholegrain loops $(P=0.01)$ produced a significant increase in the Bacteroides-Prevotella group after $10 \mathrm{~h}$ of fermentation. Granola $(P=0.01)$ fermentation resulted in a significant increase in the Lactobacillus-Enterococcus group after $24 \mathrm{~h}$, while $100 \%$ wholegrain aggregate $(P=0 \cdot 04)$ and $70 \%$ wholegrain loops $(P=0 \cdot 01)$ resulted in significant increases after $10 \mathrm{~h}$. Granola $(P<0 \cdot 01)$ and instant porridge $(P=0.04)$ resulted in a significant increase in the Clostridium bistolyticum subgroup after $24 \mathrm{~h}$ fermentation. Porridge $(P<0 \cdot 01)$ and $100 \%$ wholegrain aggregate $(P=0.03)$ fermentation resulted in a decrease in the Clostridium histolyticum subgroup after $24 \mathrm{~h}$. No significant changes in the Ruminococcus-EubacteriumClostridium cluster were observed for any of the fermentations.

\section{Comparison of treatment effects on bacterial group populations over $24 \mathrm{~h}$ fermentation}

No significant differences in the changes in the BacteroidesPrevotella or Lactobacillus-Enterococcus groups were observed among treatments. Changes in Bifidobacterium, Atopobium and Clostridium histolyticum populations compared with cellulose were significantly higher for all test substrates $(P<0 \cdot 01)$ at $24 \mathrm{~h}$. The increase seen in Clostridium bistolyticum population after instant porridge fermentation was significantly higher compared with the decrease in this population observed after jumbo porridge oats $(P=0 \cdot 04)$ and $100 \%$ wholegrain aggregate 
Table 2. Bacterial populations ( $\log _{10}$ cells $/ \mathrm{ml}$ batch culture fluid) in $\mathrm{pH}$-controlled and stirred batch cultures at $0,5,10$ and $24 \mathrm{~h}$ using oligofructose as a positive control to compare the microbiota-modulating abilities of different processed breakfast cereals

(Mean values with their standard errors)

\begin{tabular}{|c|c|c|c|c|c|c|c|c|c|c|c|c|c|c|c|}
\hline \multirow[b]{2}{*}{ Treatment } & \multirow[b]{2}{*}{ Time (h) } & \multicolumn{2}{|c|}{$\begin{array}{l}\text { Total cell } \\
\text { population }\end{array}$} & \multicolumn{2}{|c|}{$\begin{array}{l}\text { Atopobium cluster } \\
\text { and most } \\
\text { Coriobacteriaceae spp. }\end{array}$} & \multicolumn{2}{|c|}{$\begin{array}{l}\text { Bacteroides- } \\
\text { Prevotella } \\
\text { group }\end{array}$} & \multicolumn{2}{|c|}{$\begin{array}{l}\text { Bifidobacterium } \\
\text { genus }\end{array}$} & \multicolumn{2}{|c|}{$\begin{array}{l}\text { Ruminococcus- } \\
\text { Eubacterium- } \\
\text { Clostridium cluster }\end{array}$} & \multicolumn{2}{|c|}{$\begin{array}{l}\text { Clostridium } \\
\text { histolyticum } \\
\text { subgroup }\end{array}$} & \multicolumn{2}{|c|}{$\begin{array}{l}\text { Lactobacillus- } \\
\text { Enterococcus } \\
\text { group }\end{array}$} \\
\hline & & Mean & SE & Mean & SE & Mean & $\mathrm{SE}$ & Mean & SE & Mean & SE & Mean & SE & Mean & $\mathrm{SE}$ \\
\hline \multirow[t]{4}{*}{ Oligofructose } & 0 & $9 \cdot 2$ & $0 \cdot 1$ & $7 \cdot 4$ & 0.0 & $8 \cdot 1$ & 0.1 & $7 \cdot 7$ & 0.1 & $8 \cdot 1$ & 0.2 & $7 \cdot 6$ & 0.1 & 7.5 & 0.1 \\
\hline & 5 & $9 \cdot 7^{\star \star}$ & 0.1 & $7 \cdot 8^{\star}$ & 0.1 & $8 \cdot 3$ & 0.1 & $8 \cdot 1$ & 0.2 & 8.2 & 0.2 & 7.9 & 0.1 & 7.6 & 0.2 \\
\hline & 10 & $9 \cdot 8^{\star \star}$ & 0.1 & $8 \cdot 1^{\star *}$ & 0.0 & 8.5 & 0.1 & $8 \cdot 2$ & 0.1 & $8 \cdot 3$ & 0.3 & 8.0 & 0.1 & $7 \cdot 8$ & 0.0 \\
\hline & 24 & $10 \cdot 1^{\star *}$ & 0.2 & $8 \cdot 3^{\star *}$ & 0.1 & 8.4 & 0.1 & $8 \cdot 4^{*}$ & 0.2 & 8.4 & 0.1 & $7 \cdot 6$ & 0.1 & 7.5 & 0.2 \\
\hline \multirow[t]{4}{*}{ JPO } & 0 & $9 \cdot 2$ & 0.2 & $7 \cdot 7$ & 0.1 & $7 \cdot 7$ & 0.2 & 7.6 & 0.2 & 8.0 & 0.1 & 7.6 & 0.0 & 7.4 & 0.1 \\
\hline & 5 & 9.4 & 0.3 & 7.9 & 0.1 & $8 \cdot 1$ & 0.3 & 7.9 & 0.3 & 7.8 & 0.1 & 7.4 & 0.1 & 7.4 & 0.1 \\
\hline & 10 & $9 \cdot 7$ & 0.1 & $8 \cdot 1^{*}$ & 0.0 & 8.5 & 0.2 & 8.0 & 0.1 & $8 \cdot 2$ & 0.3 & $7 \cdot 1^{\star \star}$ & 0.1 & $7 \cdot 6$ & 0.1 \\
\hline & 24 & $9 \cdot 8^{*}$ & 0.2 & 7.6 & 0.0 & 8.5 & 0.0 & $8 \cdot 1^{*}$ & 0.1 & $8 \cdot 3$ & 0.2 & $6 \cdot 8^{\star \star}$ & 0.1 & 7.5 & 0.2 \\
\hline \multirow[t]{4}{*}{ IP } & 0 & 9.0 & 0.1 & 7.5 & 0.1 & $7 \cdot 7$ & 0.2 & 7.5 & 0.2 & 8.0 & 0.1 & 7.4 & 0.1 & 7.5 & 0.0 \\
\hline & 5 & $9 \cdot 4$ & 0.1 & 7.5 & 0.0 & 8.0 & 0.2 & 7.9 & 0.2 & $7 \cdot 8$ & 0.0 & 7.5 & 0.0 & $7 \cdot 6$ & 0.0 \\
\hline & 10 & $9 \cdot 7^{\star \star}$ & 0.1 & $7 \cdot 7$ & 0.1 & $8 \cdot 5^{\star \star}$ & 0.1 & $8 \cdot 1^{\star *}$ & 0.1 & $8 \cdot 1$ & 0.2 & 7.5 & 0.0 & $7 \cdot 7$ & 0.1 \\
\hline & 24 & $9 \cdot 8^{\star \star}$ & 0.0 & 7.8 & 0.0 & $8 \cdot 5^{\star}$ & 0.1 & $8 \cdot 0^{*}$ & 0.2 & $8 \cdot 3$ & 0.1 & $7 \cdot 6^{\star}$ & 0.0 & $7 \cdot 8$ & 0.1 \\
\hline \multirow[t]{4}{*}{$100 \%$ WGA } & 0 & $9 \cdot 0$ & 0.0 & 7.5 & 0.0 & $7 \cdot 8$ & 0.2 & 7.5 & 0.2 & $7 \cdot 8$ & 0.1 & $7 \cdot 3$ & 0.0 & $7 \cdot 3$ & 0.1 \\
\hline & 5 & $9 \cdot 4^{\star}$ & 0.0 & $7 \cdot 7$ & 0.0 & $8 \cdot 1$ & 0.1 & 8.1 & 0.4 & 8.4 & 0.2 & $7 \cdot 3$ & 0.0 & 7.6 & 0.1 \\
\hline & 10 & $9 \cdot 6^{\star \star}$ & 0.1 & $7 \cdot 6$ & 0.1 & $8 \cdot 4^{\star \star}$ & 0.1 & $8 \cdot 4^{*}$ & 0.2 & 8.5 & 0.2 & $7 \cdot 2$ & 0.0 & $7 \cdot 7^{\star}$ & 0.1 \\
\hline & 24 & $9 \cdot 7^{\star \star}$ & 0.1 & 7.5 & 0.0 & $8 \cdot 4^{\star}$ & 0.2 & $8 \cdot 3^{*}$ & 0.2 & 8.4 & 0.0 & $7 \cdot 2^{*}$ & 0.0 & $7 \cdot 8^{\star \star}$ & 0.1 \\
\hline \multirow[t]{4}{*}{ Granola } & 0 & $9 \cdot 1$ & 0.1 & 7.5 & 0.1 & 8.0 & 0.1 & 7.5 & 0.2 & 8.0 & 0.1 & 7.4 & 0.0 & 7.5 & 0.0 \\
\hline & 5 & $9 \cdot 5^{\star}$ & 0.1 & 7.5 & 0.0 & $8 \cdot 3$ & 0.1 & $7 \cdot 7$ & 0.1 & 8.2 & 0.1 & 7.5 & 0.0 & $7 \cdot 6$ & 0.2 \\
\hline & 10 & $9 \cdot 7^{\star \star}$ & 0.0 & $7 \cdot 7^{\star \star}$ & 0.0 & $8 \cdot 5^{\star \star}$ & 0.1 & 8.4 & 0.2 & 8.5 & 0.2 & $7 \cdot 5^{\star}$ & 0.1 & $7 \cdot 7^{\star}$ & 0.0 \\
\hline & 24 & $9 \cdot 6^{\star \star}$ & 0.1 & $7 \cdot 8^{\star *}$ & 0.0 & $8 \cdot 4^{\star \star}$ & 0.0 & $8 \cdot 3^{*}$ & 0.3 & 8.4 & 0.2 & $7 \cdot 6^{\star *}$ & 0.0 & $7 \cdot 8^{*}$ & 0.3 \\
\hline \multirow[t]{4}{*}{$70 \%$ WGL } & 0 & $9 \cdot 1$ & 0.1 & $7 \cdot 6$ & 0.1 & 8.0 & 0.2 & 7.5 & 0.2 & $8 \cdot 1$ & 0.0 & 7.8 & 0.1 & 7.4 & 0.1 \\
\hline & 5 & 9.5 & 0.1 & 7.6 & 0.0 & 8.2 & 0.1 & 8.1 & 0.3 & 8.1 & 0.2 & 7.8 & 0.0 & 7.4 & 0.1 \\
\hline & 10 & $9 \cdot 7^{\star \star}$ & 0.1 & $7 \cdot 7$ & 0.0 & $8 \cdot 6^{\star}$ & 0.1 & $8 \cdot 2^{*}$ & 0.2 & 8.5 & 0.2 & $7 \cdot 7$ & 0.0 & $7 \cdot 5^{\star}$ & 0.1 \\
\hline & 24 & $9 \cdot 7^{\star \star}$ & 0.1 & 7.6 & 0.1 & $8.5^{\star}$ & 0.0 & $8 \cdot 3^{*}$ & 0.2 & $8 \cdot 3$ & 0.2 & $7 \cdot 7$ & 0.1 & $7 \cdot 6^{\star \star}$ & 0.0 \\
\hline \multirow[t]{4}{*}{ Cellulose } & 0 & 9.4 & 0.1 & 7.0 & 0.1 & 7.9 & 0.3 & 7.4 & 0.1 & 8.4 & 0.1 & 6.9 & 0.3 & 7.5 & 0.0 \\
\hline & 5 & 9.5 & 0.0 & $7 \cdot 3$ & 0.1 & $8 \cdot 1$ & 0.2 & 7.5 & 0.2 & 8.2 & 0.1 & $6 \cdot 8$ & 0.3 & 7.5 & 0.0 \\
\hline & 10 & 9.5 & 0.2 & $7 \cdot 2$ & 0.2 & $8 \cdot 1$ & 0.0 & $7 \cdot 6$ & 0.2 & 8.4 & 0.0 & $6 \cdot 8$ & 0.2 & 7.5 & 0.1 \\
\hline & 24 & $9 \cdot 6$ & 0.2 & $7 \cdot 1$ & 0.2 & 8.3 & 0.2 & 7.6 & 0.2 & 8.5 & 0.3 & $6 \cdot 6$ & 0.1 & 7.5 & 0.1 \\
\hline
\end{tabular}

JPO, jumbo porridge oats, IP, instant porridge, $100 \%$ WGA, $100 \%$ wholegrain aggregate, $70 \%$ WGL, $70 \%$ wholegrain loops.

Mean value was significantly different from that at $0 \mathrm{~h}:{ }^{*} P<0.05,{ }^{\star \star} P<0.001$. 
( $P=0.04)$ fermentation. Jumbo porridge oats $(P<0 \cdot 01)$ and $100 \%$ wholegrain aggregate $(P<0.01)$ fermentations were again significantly lower for the Clostridium bistolyticum profile compared with $70 \%$ wholegrain loops fermentation. $100 \%$ Wholegrain aggregate fermentation resulted in a quicker increase in Bifidobacterium compared with granola $(P<0 \cdot 01)$. However, granola $(P<0 \cdot 01)$ and oligofructose $(P<0 \cdot 01)$ had a higher increase in Bifidobacterium compared with jumbo porridge oats. The changes seen in Atopobium populations after oligofructose fermentation were significantly higher than the changes in populations observed after $70 \%$ wholegrain loops $(P=0 \cdot 01)$ and $100 \%$ wholegrain aggregate $(P<0 \cdot 01)$ fermentation. The increase seen after jumbo porridge oat fermentation was significantly higher compared with 100\% wholegrain aggregate $(P=0 \cdot 01)$ for the Atopobium population. A significant increase among treatments was observed for cellulose compared with granola $(P<0 \cdot 01)$ and jumbo porridge oats $(P<0.01)$ for Ruminococcus-Eubacterium-Clostridium cluster changes. The total bacteria population was significantly higher when oligofructose was compared with $100 \%$ wholegrain aggregate $(P<0.01)$ and granola $(P=0.01)$.

\section{SCFA production}

Changes in SCFA concentrations after 0, 5, 10 and 24 h fermentation with the different test substrates are shown in Table 3. A significant increase in total (acetic, propionic and butyric acids combined) SCFA concentration after $10 \mathrm{~h}$ fermentation by the faecal microbiota $(P<0.05)$ was observed with all substrates tested. Acetic acid was the dominant SCFA produced in all fermentations and a significant increase in production of this SCFA was observed for cellulose $(P=0.02)$ and $100 \%$ wholegrain aggregate $(P<0 \cdot 01)$ after $10 \mathrm{~h}$ incubation, while for $70 \%$ wholegrain loops $(P<0 \cdot 01)$ and refined flakes instant porridge $(P=0.03)$ the concentration of acetate increased significantly after $5 \mathrm{~h}$. However, a significant increase in acetate was observed after $24 \mathrm{~h}$ for oligofructose $(P<0 \cdot 01)$, jumbo porridge oats $(P<0 \cdot 01)$ and granola $(P<0 \cdot 01)$. Propionate increased significantly after $10 \mathrm{~h}$ fermentation for both $70 \%$ wholegrain loops $(P<0.01)$ and $100 \%$ wholegrain aggregate $(P<0 \cdot 01)$, while oligofructose $(P<0 \cdot 01)$, cellulose $(P=0 \cdot 02)$, jumbo porridge oats $(P=0.01)$ and granola $(P<0.01)$ resulted in significant propionate production only after $24 \mathrm{~h}$. Instant porridge fermentation resulted in a significant increase after $5 \mathrm{~h}(P=0.03)$. A significant increase in butyrate was recorded

Table 3. SCFA concentrations ( $\mathrm{mmol} / \mathrm{l}$ ) in batch cultures at 0 (inoculum), 5,10 and $24 \mathrm{~h}$ using different processed breakfast cereals, as compared with oligofructose as a positive control

(Mean values with their standard errors)

\begin{tabular}{|c|c|c|c|c|c|c|c|c|c|}
\hline \multirow[b]{2}{*}{ Substrate } & \multirow[b]{2}{*}{ Time (h) } & \multicolumn{2}{|c|}{$\begin{array}{l}\text { Total SCFA } \\
\text { concentration } \\
(\mathrm{mmol} / \mathrm{l})\end{array}$} & \multicolumn{2}{|c|}{$\begin{array}{l}\text { Acetic acid } \\
\text { concentration } \\
(\mathrm{mmol} / \mathrm{l})\end{array}$} & \multicolumn{2}{|c|}{$\begin{array}{l}\text { Propionic acid } \\
\text { concentration } \\
(\mathrm{mmol} / \mathrm{l})\end{array}$} & \multicolumn{2}{|c|}{$\begin{array}{l}\text { Butyric acid } \\
\text { concentration } \\
(\mathrm{mmol} / \mathrm{l})\end{array}$} \\
\hline & & Mean & SE & Mean & SE & Mean & SE & Mean & SE \\
\hline \multirow[t]{4}{*}{ Oligofructose } & 0 & 1.2 & 0.1 & 0.8 & 0.1 & 0.2 & 0.0 & 0.2 & 0.1 \\
\hline & 5 & $2 \cdot 8$ & 0.1 & $2 \cdot 1$ & 0.1 & 0.5 & 0.0 & 0.2 & 0.0 \\
\hline & 10 & $14 \cdot 6^{*} \dagger$ & 3.9 & $12 \cdot 9$ & 3.8 & 1.2 & 0.0 & 0.5 & 0.1 \\
\hline & 24 & $46^{\star} † \ddagger$ & $2 \cdot 4$ & $32 \cdot 3^{\star} \dagger \ddagger$ & 2.9 & $7 \cdot 1^{\star} \dagger \ddagger$ & 1.3 & $6 \cdot 6^{\star} \pitchfork \ddagger$ & 1.7 \\
\hline \multirow[t]{4}{*}{ JPO } & 0 & $1 \cdot 1$ & 0.1 & 0.8 & 0.0 & 0.2 & 0.0 & 0.1 & 0.0 \\
\hline & 5 & 2.5 & $1 \cdot 1$ & $2 \cdot 2$ & $1 \cdot 1$ & 0.2 & 0.0 & 0.1 & 0.0 \\
\hline & 10 & $10 \cdot 1$ & 2.9 & 8.7 & 2.9 & 1.2 & 0.1 & $0 \cdot 1$ & 0.0 \\
\hline & 24 & $35 \cdot 1^{*} \dagger \ddagger$ & 6.5 & $26 \cdot 1^{*} \dagger \ddagger$ & 3.8 & $8 \cdot 0^{\star} \dagger \ddagger$ & $2 \cdot 3$ & 0.9 & 0.5 \\
\hline \multirow[t]{4}{*}{ IP } & 0 & 1.2 & 0.1 & 0.9 & 0.0 & 0.2 & 0.0 & 0.2 & 0.0 \\
\hline & 5 & $12 \cdot 5^{\star}$ & 1.5 & $10^{\star}$ & 1.4 & $2 \cdot 3^{\star}$ & 0.4 & $0 \cdot 1$ & 0.1 \\
\hline & 10 & $31 \cdot 2^{*} \dagger$ & 1.4 & $23 \cdot 7^{\star} \dagger$ & 1.5 & $4 \cdot 7^{\star} \dagger$ & 0.6 & $2 \cdot 8$ & 1.2 \\
\hline & 24 & $42 \cdot 8^{\star} \dagger \ddagger$ & $2 \cdot 1$ & $31 \cdot 9^{*} \dagger \ddagger$ & 2.5 & $7 \cdot 1^{*} \dagger \ddagger$ & 0.5 & $3 \cdot 7^{\star} \dagger$ & 0.1 \\
\hline \multirow[t]{4}{*}{$100 \%$ WGA } & 0 & 0.8 & 0.3 & 0.6 & 0.2 & $0 \cdot 1$ & 0.1 & 0.1 & 0.0 \\
\hline & 5 & $12 \cdot 6^{*}$ & $2 \cdot 1$ & $10 \cdot 1$ & 1.3 & $2 \cdot 0$ & 0.6 & 0.5 & 0.3 \\
\hline & 10 & $28 \cdot 9^{*} \dagger$ & 0.6 & $23 \cdot 3^{*} \dagger$ & 1.6 & $4 \cdot 4^{*} \dagger$ & 0.7 & $1 \cdot 2$ & 0.3 \\
\hline & 24 & $41 \cdot 8^{\star} \dagger \ddagger$ & $3 \cdot 2$ & $31 \cdot 7^{\star} \dagger \ddagger$ & $2 \cdot 8$ & $5 \cdot 8^{*} \dagger$ & 0.0 & $4 \cdot 3^{*} † \ddagger$ & 0.4 \\
\hline \multirow[t]{4}{*}{ Granola } & 0 & 0.7 & 0.3 & 0.5 & 0.3 & 0.1 & 0.1 & 0.1 & 0.0 \\
\hline & 5 & 0.7 & 0.0 & 0.0 & 0.0 & 0.0 & 0.0 & 0.0 & 0.0 \\
\hline & 10 & 9.7 & 1.9 & $9 \cdot 1$ & 1.9 & 0.5 & 0.0 & $0 \cdot 1$ & 0.0 \\
\hline & 24 & $37.4^{*} \dagger \ddagger$ & $6 \cdot 2$ & $27 \cdot 6^{\star} \dagger \ddagger$ & 4.4 & $8 \cdot 0^{*} \dagger \ddagger$ & $1 \cdot 0$ & 1.8 & 0.8 \\
\hline \multirow{4}{*}{$70 \%$ WGL } & 0 & 1.2 & 0.2 & 0.9 & 0.1 & 0.2 & 0.1 & 0.1 & 0.0 \\
\hline & 5 & $18 \cdot 8^{\star}$ & 1.9 & $15 \cdot 1^{\star}$ & $2 \cdot 1$ & 1.8 & 0.2 & 1.8 & 0.5 \\
\hline & 10 & $33 \cdot 6^{*} \dagger$ & 1.0 & $26 \cdot 1^{*} \dagger$ & $1 \cdot 1$ & $3 \cdot 5^{\star}$ & 0.5 & $3.9^{*}$ & 0.6 \\
\hline & 24 & $44.7^{\star} \dagger \ddagger$ & 0.7 & $32 \cdot 7^{*} \dagger$ & 1.4 & $7 \cdot 3^{*} \dagger \ddagger$ & 0.4 & $4 \cdot 7^{\star}$ & 1.1 \\
\hline \multirow[t]{4}{*}{ Cellulose } & 0 & 0.3 & $0 \cdot 1$ & 0.4 & 0.1 & 0.0 & 0.0 & 0.0 & 0.0 \\
\hline & 5 & 1.3 & 0.7 & 0.9 & 0.4 & 0.2 & 0.2 & 0.2 & 0.1 \\
\hline & 10 & $2 \cdot 7^{\star}$ & 1.0 & $1.9^{\star}$ & 0.6 & 0.5 & 0.2 & 0.3 & 0.2 \\
\hline & 24 & $4.5^{*} \dagger$ & 0.7 & $3.1^{*} \dagger$ & 0.3 & $0.8^{\star}$ & 0.3 & 0.6 & 0.1 \\
\hline
\end{tabular}

JPO, jumbo porridge oats, IP, instant porridge, 100\%WGA, 100\% wholegrain aggregate, $70 \%$ WGL, $70 \%$ wholegrain loops.

${ }^{*}$ Mean value was significantly different from that at $0 \mathrm{~h}(P<0.05)$.

† Mean value was significantly different from that at $5 \mathrm{~h}(P<0.05)$.

$\ddagger$ Mean value was significantly different from that at $10 \mathrm{~h}(P<0.05)$. 
after $10 \mathrm{~h}$ fermentation for $70 \%$ wholegrain loops $(P=0.03)$ and significant $(P<0.01)$ production was detected after $24 \mathrm{~h}$ for all other substrates except cellulose.

\section{Glycaemic index of cereal products}

All participants completed the study. Their glycaemic responses to all cereals were in the 'normal' range for non-diabetic subjects. The mean glycaemic response curves of the test cereals and the two glucose references are shown in Fig. 1. The GI values were: $100 \%$ wholegrain aggregate, 40 (SEM 22.6 )\%; granola, 44 (SEM 12.9)\%; jumbo porridge oats, 50 (SEM $11.9) \% ; 70 \%$ wholegrain loops, 74 (SEM 13.8)\%; instant porridge, 88 (SEM 13.9)\%. The GI values for granola $(P<0.01)$ and $100 \%$ wholegrain aggregate $(P=0 \cdot 03)$ were significantly lower than that for $70 \%$ wholegrain loops. No significant difference was observed between the $25 \mathrm{~g}$ glucose reference and instant porridge, jumbo porridge oats or among refined flakes instant porridge and jumbo porridge oats or granola.

\section{Discussion}

Wholegrain cereal consumption has been linked to reduction in a number of chronic diseases of the Western population including diabetes, obesity and $\mathrm{CVD}^{(28-30)}$. The aim of the present study was to investigate the impact of five wholegrain breakfast cereals containing different grains, and processed to different extents, on fermentation profiles within the

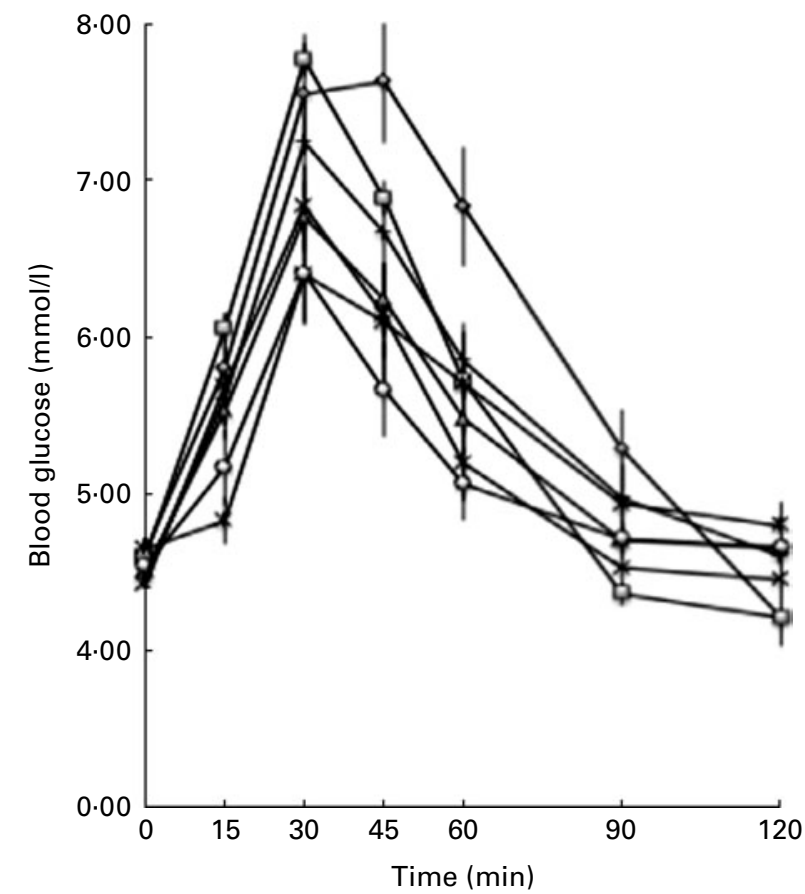

Fig. 1. Fasting and postprandial capillary blood glucose responses to the test cereals over $120 \mathrm{~min}$. The values at different time points were based on twenty-four blood samplings for each glucose reference and on twelve blood samplings for test foods. Data from twelve volunteers were averaged. Values are means, with standard errors represented by vertical bars. $\left(-\diamond_{-}\right), 50 \mathrm{~g}$ Glucose; (- $\square-)$, $25 \mathrm{~g}$ glucose; $(-\Delta-)$, jumbo porridge oats; (-X-), instant porridge; $\left(-^{\star}-\right)$, $100 \%$ wholegrain aggregate; $(-\bigcirc-)$, granola; $(-+-), 70 \%$ wholegrain loops. human gut microbiota, compared with the confirmed prebiotic, oligofructose, and to determine the cereal's GI values to allow investigation of combined wholegrain potential mechanisms of protection.

The data from the present study further demonstrated that extensively processed wholegrain cereals resulted in higher GI responses compared with minimally processed wholegrain cereals (i.e. jumbo porridge oats, granola and 100\% wholegrain aggregate compared with $70 \%$ wholegrain loops and instant porridge). In addition, processing of the wholegrain cereals affected the microbiota-modulating activity of the non-digestible components of the breakfast cereals. This has important implications in relation to dietary therapy and cardiometabolic risk reduction and for the definition of a wholegrain product.

In the present study, fermentation of the non-digestible components resulting from in vitro digestion of five commonly consumed breakfast cereals was studied. A large effect on the fermentation profile in relation to changes of the dominant members of the gut microbiota and metabolites produced was reported. Significant increases in the growth of the Bifidobacterium genus and the Lactobacillus-Enterococcus group were observed in the case of granola, 100\% wholegrain aggregate and $70 \%$ wholegrain loops, which supports previous in vivo and in vitro studies using wheat, maize and oat grain breakfast cereals $^{(13,14,18)}$. Although the non-digestible components of the cereals involved in the observed microbiota changes have not been identified, we postulate that RS is probably a key constituent. Previously it has been documented by Livesey et al. that the physical form of barley grain influences the digestion of its starch content ${ }^{(31)}$. This study observed that only $2 \%$ of starch remained undigested after finely milled barley was consumed compared with $17 \%$ after flaked barley was eaten. After flaked barley digestion it was observed that some oligosaccharides persisted into the colon, but largely the undigested carbohydrate was intact unpitted starch granules bound by intact cell walls. It was concluded that possibly the botanical source of cereals and processing, other than retrogradation of starch, are important determinants of starch digestibility and energy value. In two previous studies we documented that the oat flake size and toasting of wheat flakes significantly affected gut microbiota modulation and activity ${ }^{(19,32)}$. Altering the oat flake size had a negative impact on gut microbiota modulation, with the smaller flakes resulting in less prebiotic ability than the larger flakes ${ }^{(18)}$. Scanning electron microscopy was used to examine the physical structure of wheat flakes before, during and after the toasting process. It was observed that the number of intact starch granules decreased and that the structure of the grain was significantly disrupted by this common process ${ }^{(31)}$. The results from our previous investigations along with the present study correspond with the conclusion made by Livesey et al. in that botanical structure and the effect processing has on structure will make an impact on digestibility of carbohydrates and in turn the potential to alter gut microbiota populations and activity.

Acetate is the most abundant SCFA produced in the colon while propionate and butyrate are usually produced in roughly equal proportions ${ }^{(16)}$. In the present study all cereal 
fermentation resulted in significant increases in acetate and propionate concentrations. Previous studies have reported different SCFA profiles after fermentation of non-digestible components of wholegrains (for example, $\beta$-glucan and arabinoxylan $)^{(33,34)}$. To date only two studies have investigated the impact of feeding wholegrain breakfast cereals (wheat and maize) on microbiota ${ }^{(13,14)}$. These studies did not detect any changes in faecal SCFA concentrations, which is not wholly surprising, as SCFA are readily absorbed in the colon. Butyrate plays a major role in colonocyte proliferation and differentiation $^{(35)}$, with 70-90\% metabolised by the gut wall cells. Its production has been linked to inhibiting cancer development and has been shown to inhibit cell proliferation ${ }^{(36)}$. Another potential mechanism of action is that the drop in $\mathrm{pH}$ as a result of increased total SCFA production decreases the solubility of free bile acids which, in turn, decreases secondary bile acids that have potential tumour-promoter activity ${ }^{(37)}$.

$\mathrm{RS}$ is a dietary fibre component of wholegrains and its fermentation commonly results in butyrate production. Dietary RS intakes and faecal butyrate levels are seen to be elevated in populations at low risk of diet-related large-bowel diseases ${ }^{(38)}$. This raises the possibility that greater RS consumption could be of health benefit. RS has most recently been suggested as a prebiotic by Bird et al., as most forms stimulate specific beneficial bacteria, resulting in elevated total SCFA and butyrate concentrations and a consequent benefit to the host ${ }^{(39)}$. Furthermore, cross-feeding may also occur between bifidobacteria and butyrate-producing colonic bacteria, which may explain the significant increase in acetate (from bifidobacteria) and butyrate production seen in the present study ${ }^{(40)}$.

In conclusion, the present study has shown that consumption of wholegrain breakfast cereals has the potential to beneficially modulate the gut microbiota. Significant growth of the Bifidobacterium genus and, in the case of $100 \%$ wholegrain aggregate, granola and $70 \%$ wholegrain loops, LactobacillusEnterococcus group was observed. In addition, the GI of the highly processed cereals was greater than the minimally processed cereals. The $100 \%$ wholegrain oat aggregate cereal had the greatest prebiotic potential and lowest GI which, if consumed, could result in cardiometabolic benefit. However, to determine the impact of breakfast cereals with low GI and prebiotic traits on cardiometabolic risk, appropriately powered, randomly controlled human dietary intervention studies are required.

\section{Acknowledgements}

The present study was supported by the Reading Endowment Trust Fund (RETF) and The Jordans \& Ryvita Company Limited (Holme Mills, Biggleswade, SG18 9JY, UK). M. L. C., J. A. L. and K. M. T. designed the study; M. L. C. drafted the manuscript and all authors read, commented on and approved the submitted version. J. A. L. sits on a number of British Government advisory committees including the Scientific Advisory Committee for Nutrition (SACN). Funds for research studies and studentships have been supplied by Unilever and Sugar Nutrition UK. Between October 1999 and May 2010, K. M. T. worked in the Department of Food and Nutritional Sciences, University of Reading. Funds for research studies and studentships have been supplied by Cereal Partner's UK, Nestlé, Beneo-Orafti, Müller Dairies, Bayer, Unilever, Danisco, Yakult, GSK and Novartis. K. M. T. now works at Fondazione Edmund Mach, Italy, a publicly funded research institute and receives funding from local government and the Marie-Curie Foundation. M. L. C. has no conflicts of interest.

\section{References}

1. Amano Y, Kawakubo K, Lee JS, et al. (2004) Correlation between dietary glycemic index and cardiovascular disease risk factors among Japanese women. Eur J Clin Nutr 58, 1472-1478.

2. Liu S, Manson JE, Stampfer MJ, et al. (2000) A prospective study of whole-grain intake and risk of type 2 diabetes mellitus in US women. Am J Public Health 90, 1409-1415.

3. van de Vijver LP, van den Bosch LM, van den Brandt PA, et al. (2009) Whole-grain consumption, dietary fibre intake and body mass index in the Netherlands cohort study. Eur J Clin Nutr 63, 31-38.

4. Chan JM, Wang F \& Holly EA (2007) Whole grains and risk of pancreatic cancer in a large population-based case-control study in the San Francisco Bay Area, California. Am J Epidemiol 166, 1174-1185.

5. Food and Drug Administration, HHS (2008) Food labeling: health claims; soluble fiber from certain foods and risk of coronary heart disease. Final rule. Fed Reg 73, 47828-47829.

6. Jacobs DR Jr \& Gallaher DD (2004) Whole grain intake and cardiovascular disease: a review. Curr Atheroscler Rep 6 , 415-423.

7. DeFronzo RA (1988) Lilly lecture 1987. The triumvirate: $\beta$-cell, muscle, liver. A collusion responsible for NIDDM. Diabetes 37, 667-687.

8. Du H, van der ADL, van Bakel MM, et al. (2008) Glycemic index and glycemic load in relation to food and nutrient intake and metabolic risk factors in a Dutch population. Am J Clin Nutr 87, 655-661.

9. Schatzkin A, Mouw T, Park Y, et al. (2007) Dietary fiber and whole-grain consumption in relation to colorectal cancer in the NIH-AARP Diet and Health Study. Am J Clin Nutr 85, 1353-1360.

10. Pereira MA, Swain J, Goldfine AB, et al. (2004) Effects of a low-glycemic load diet on resting energy expenditure and heart disease risk factors during weight loss. JAMA 292, 2482-2490.

11. Giovannucci E (1995) Insulin and colon cancer. Cancer Causes Control 6, 164-179.

12. Atkinson FS, Foster-Powell K \& Brand-Miller JC (2008) International tables of glycemic index and glycemic load values: 2008. Diabetes Care 31, 2281-2283.

13. Costabile A, Klinder A, Fava F, et al. (2008) Whole-grain wheat breakfast cereal has a prebiotic effect on the human gut microbiota: a double-blind, placebo-controlled, crossover study. Br J Nutr 99, 110-120.

14. Carvalho-Wells AL, Helmolz K, Nodet C, et al. (2010) Determination of the in vivo prebiotic potential of a maize-based whole grain breakfast cereal: a human feeding study. $\mathrm{Br} J$ Nutr 104, 1353-1356.

15. Macfarlane GT, Blackett KL, Nakayama T, et al. (2009) The gut microbiota in inflammatory bowel disease. Curr Pharm Des 15, 1528-1536.

16. Roediger WE (1982) Utilization of nutrients by isolated epithelial cells of the rat colon. Gastroenterology 83, 424-429. 
17. Blottiere HM, Buecher B, Galmiche JP, et al. (2003) Molecular analysis of the effect of short-chain fatty acids on intestinal cell proliferation. Proc Nutr Soc 62, 101-106.

18. Bornet FR, Brouns F, Tashiro Y, et al. (2002) Nutritional aspects of short-chain fructooligosaccharides: natural occurrence, chemistry, physiology and health implications. Dig Liver Dis 34, Suppl. 2, S111-S120.

19. Connolly ML, Lovegrove JA \& Tuohy KM (2010) In vitro evaluation of the microbiota modulation abilities of different sized whole oat grain flakes. Anaerobe 16, $483-488$

20. Daims H, Stoecker K \& Wagner M (2005) Molecular Microbial Ecology. New York: Taylor \& Francis Group.

21. Rycroft CE, Jones MR, Gibson GR, et al. (2001) A comparative in vitro evaluation of the fermentation properties of prebiotic oligosaccharides. J Appl Microbiol 91, 878-887.

22. Langendijk PS, Schut F, Jansen GJ, et al. (1995) Quantitative fluorescence in situ hybridization of Bifidobacterium spp. with genus-specific 16S rRNA-targeted probes and its application in fecal samples. Appl Environ Microbiol 61, 3069-3075.

23. Harmsen HJ, Elferrich P, Schut F, et al. (1999) A 16S rRNA targeted probe for detection of lactobacilli and enterococci in faecal samples by fluorescent in situ hybridization. Microbiol Ecol Health Dis 11, 3-12.

24. Manz W, Amann R, Ludwig W, et al. (1996) Application of a suite of 16S rRNA-specific oligonucleotide probes designed to investigate bacteria of the phylum Cytophaga-Flavobacter-Bacteroides in the natural environment. Microbiology 142, 1097-1106.

25. Franks AH, Harmsen HJ, Raangs GC, et al. (1998) Variations of bacterial populations in human feces measured by fluorescent in situ hybridization with group-specific $16 \mathrm{~S}$ rRNA-targeted oligonucleotide probes. Appl Environ Microbiol 64, 3336-3345.

26. Harmsen HJ, Wildeboer-Veloo AC, Grijpstra J, et al. (2000) Development of 16S rRNA-based probes for the Coriobacterium group and the Atopobium cluster and their application for enumeration of Coriobacteriaceae in human feces from volunteers of different age groups. Appl Environ Microbiol 66, 4523-4527.

27. Zhao G, Nyman M \& Jönsson JA (2006) Rapid determination of short-chain fatty acids in colonic contents and faeces of humans and rats by acidified water-extraction and direct-injection gas chromatography. Biomed Chromatogr 20, 674-682.
28. Steffen LM, Jacobs DR Jr, Stevens J, et al. (2003) Associations of whole-grain, refined-grain, and fruit and vegetable consumption with risks of all-cause mortality and incident coronary artery disease and ischemic stroke: the Atherosclerosis Risk in Communities (ARIC) Study. Am J Clin Nutr 78, 383-390.

29. Liu S, Manson JE, Buring JE, et al. (2002) Relation between a diet with a high glycemic load and plasma concentrations of high-sensitivity C-reactive protein in middle-aged women. Am J Clin Nutr 75, 492-498.

30. Leeds AR (2002) Glycemic index and heart disease. Am J Clin Nutr 76, 286S-289S.

31. Livesey G, Wilkinson JA, Roe M, et al. (1995) Influence of the physical form of barley grain on the digestion of its starch in the human small intestine and implications for health. Am J Clin Nutr 61, 75-81.

32. Connolly ML, Lovegrove JA \& Tuohy KM (2012) In vitro fermentation characteristics of whole grain wheat flakes and the effect of toasting on prebiotic potential. I Med Food 14, 33-43.

33. Hughes SA, Shewry PR, Gibson GR, et al. (2008) In vitro fermentation of oat and barley derived $\beta$-glucans by human faecal microbiota. FEMS Microbiol Ecol 64, 482-493.

34. Hughes SA, Shewry PR, Li L, et al. (2007) In vitro fermentation by human fecal microflora of wheat arabinoxylans. J Agric Food Chem 55, 4589-4595.

35. Chai F, Evdokiou A, Young GP, et al. (2000) Involvement of $\mathrm{p} 21^{\mathrm{Waf} 1 / \mathrm{Cip} 1}$ and its cleavage by DEVD-caspase during apoptosis of colorectal cancer cells induced by butyrate. Carcinogenesis 21, 7-14.

36. Scheppach W \& Weiler F (2004) The butyrate story: old wine in new bottles? Curr Opin Clin Nutr Metab Care 7 , 563-567.

37. Cheah PY \& Bernstein H (1990) Modification of DNA by bile acids: a possible factor in the etiology of colon cancer. Cancer Lett 49, 207-210.

38. Brouns F, Kettlitz B \& Arrigoni E (2002) Resistant starch and 'the butyrate revolution'. Trends Food Sci Technol 13, $251-261$.

39. Bird AR, Conlon MA, Christophersen CT, et al. (2010) Resistant starch, large bowel fermentation and a broader perspective of prebiotics and probiotics. Benef Microbes $\mathbf{1}$, 423-431.

40. De Vuyst L \& Leroy F (2011) Cross-feeding between bifidobacteria and butyrate-producing colon bacteria explains bifdobacterial competitiveness, butyrate production, and gas production. Int J Food Microbiol 149, 73-80. 